\title{
Cloning of Bacillus subtilis phytase gene construct in Escherichia coli
}

\author{
Mahdiyar Iravani Saadi ${ }^{1}$, Abbas Doosti ${ }^{2}$, Heeva Jalali ${ }^{3 *}$, Ehsan Nabi Abdolyousefi ${ }^{1}$, Mansooreh \\ Hooshiyar $^{4}$, Reza Tabrizi ${ }^{5}$, Esmat Noshadi ${ }^{1,2^{*}}$ \\ ${ }^{1}$ Hematology Research Center, Shiraz University of Medical Sciences, Shiraz, Iran \\ ${ }^{2}$ Biotechnology Research Center, Islamic Azad University, Shahrekord Branch, Shahrekord, Iran \\ ${ }^{3}$ Department of Animal Science, Faculty of Agriculture, University of Kurdistan, Sanandaj, Iran \\ ${ }^{4}$ Department of Microbiology and Microbial Biotechnology, Faculty of Life Sciences and Biotechnology, \\ Shahid Beheshti University, Tehran, Iran \\ ${ }^{5}$ Non-Communicable Diseases Research Center, Fasa University of Medical Sciences, Fasa, Iran
}

Received: January 2021, Accepted: August 2021

\begin{abstract}
Background and Objectives: Phytase has a hydrolysis function of phytic acid, which yields inorganic phosphate. Bacillus species can produce thermostable alkaline phytase. The aim of this study was to isolate and clone a Phytase gene (Phy) from Bacillus subtilis in Escherichia coli.

Materials and Methods: In this study, the extracellular PhyC gene was isolated from Bacillus subtilis Phytase C. After purification of the bands, DNA fragment of Phy gene was cloned by T/A cloning technique, and the clone was transformed into Escherichia coli. Afterward, the pGEM-Phy was transferred into E. coli Top-10 strain and the recombinants were plated on LB agar containing $100 \mu \mathrm{g} / \mathrm{ml}$ ampicillin. The colonization of $1171 \mathrm{bp}$ of gene Phytase $C$ was confirmed by PCR. The presence of gene-targeting in vector was confirmed with enzymatic digestion by XhoI and XbaI restriction enzymes.

Results: The Phytase gene was successfully cloned in E. coli. The result of cloning of 1171 bp Phytase gene was confirmed by PCR assay.

Conclusion: Our impression of this article is that several methods, such as using along with microbial, plant phytase reproduction, or low-phytic acid corn may be the better way from a single phytase.
\end{abstract}

Keywords: Bacillus subtilis; Cloning; Escherichia coli; Phytase; Probiotics

\section{INTRODUCTION}

Phytate (Myo-inositol 1,2,3,4,5,6-hexakis dihydrogen phosphate), is the major source of inositol $(1,2)$ and the main storage form of phosphorus $(\mathrm{P})$, typically accounting for $60-90 \%$ of the total $\mathrm{P}$ content of oilseed crops, cereals and legumes (3). Phytate acts as an antinutrient factor since it causes mineral deficiency by chief dietary minerals such as, $\mathrm{Fe}^{2+}, \mathrm{Zn}^{2+}$, $\mathrm{Mg}^{2+}$ and $\mathrm{Ca}^{2+}$ (4). Making these complexes is basically non absorption from the human gastrointestinal tract (5) and monogastric animals, such as poultry, pig and fish (6). Therefore, this creates problems in the usability of P in their meal (7). Suzuki et al. dis-

\footnotetext{
*Corresponding author: Heeva Jalali, MSc, Department of Animal Science, Faculty of Agriculture, University of Kurdistan, Sanandaj, Iran. Tel: +98-918-9786698_Fax: +98-871-33620553_Email: heeva.jalali@uok.ac.ir

"Corresponding author: Esmat Noshadi, Ph.D, Hematology Research Center, Shiraz University of Medical Sciences, Shiraz, Iran; Biotechnology Research Center, Islamic Azad University, Shahrekord Branch, Shahrekord, Iran. Tel: +98-36122263 Fax: +98-71$36122261 \quad$ Email: e.noshadi@yahoo.com
} 
covered this enzyme in 1907 (8). Phytases, myo-inositol hexakisphosphate hydrolases, are a specific class of phosphatases (9) which are capable of hydrolysis of Myo-inositol- (1,2,3,4,5,6)-hexakisphosphate and inorganic P (10). Phytase releases at least one phosphate from phytate (11); this is supposing as a principal metabolic process in many microscopic organisms (1). Phytate remains in monogastric- beast -derived dung causing serious $\mathrm{P}$ pollution, contributing to accumulate of water resource (1). Today, enhancement of public concern regarding the environmental effect of high $\mathrm{P}$ levels in animal excrement has driven phytase usage in animal diet and the biotechnological importance of phytase $(12,13)$.

Phytases are generally widespread in nature, for example, it discovered in plants, animal $(14,15)$, and in microorganisms $(16,17)$. Most of the methodical work has been done on organism's phytases, mainly on those originating from filamentous fungi such as Aspergillus ficuum (18), A. fumigatus (19), and Cladosporium species (20); yeasts phytases like Schwanniomyces occidentalis (21), Pichia anomala (14); Gram-Positive bacteria such as Bacillus subtilis (22); and gram-negative bacteria such as Escherichia coli (23), Pseudomonas bacteria (24), Klebsiella spp. (25). Overview of bacterial phytase genes by genetic engineering has enhanced the bioavailability of numerous inorganic nutrients (26). Choice dietary enrichment of animal feed and the expulsion problem of $\mathrm{P}$ pollution opened up bright prospects for the study on this enzyme.

Now, the main source of organisms important for the production of phytase is bacteria isolated from various sources (27), such as Bacillus phytase. This kind of enzyme has been studied widely, because these kinds of phytase have unique features, and also the feasibility of their mass production for applicability in animal nutrition (28). Bacillus subtilis is a Gram-positive, rod-shaped and spore-forming bacteria (29) that produces many secondary metabolites (30) such as subtilin (31), a-amylase (32), phytase, and nattokinase (33). This organism is not considered pathogenic and (34) the optimal temperature is $25-35^{\circ} \mathrm{C}(11)$.

Numerous phytase genes have been successfully cloned in several bacterial hosts, transgenic maize, and pigs. E. coli is often selected as a primary host microorganism for the production of this enzyme (35). In 2003, it has been reported that the expression of Bacillus phytase in E. coli is amounted to about
$20 \%$ of the soluble proteins (24). In the present study, we aimed to clone a novel phytase gene $(P h y C)$ from Bacillus subtilis in E. coli for future extracellular phytase production.

\section{MATERIALS AND METHODS}

Bacterial strains and plasmids. B. subtilis was used as a source of chromosomal DNA. Standard strain of B. subtilis bacteria was prepared in the Department of Microbiology Pasteur Institute of Iran and was grown at $37^{\circ} \mathrm{C}$ in Luria Bertani broth (LB broth) and LB agar plates. Medium was supplemented with ampicillin $(100 \mathrm{mg} / \mathrm{ml})$. Grown colonies were biochemically confirmed as B. subtilis positive.

Bacillus subtilis was grown on Luria-Bertani (LB) agar plate at $28^{\circ} \mathrm{C}$ for 24 h. E. coli strain Top10F', pGEM-T easy vector (Invitrogen, San Diego, CA) was used for TA cloning (using TA cloning kit (Promega, U.S)) and pET32 vector (was used for subcloning (Novagen, Germany)) were cultured in LB broth medium overnight at $37^{\circ} \mathrm{C}$.

DNA esxtraction. Genomic DNA was isolated from bacterial colonies using DNA extraction kit (DNPTM, Cinna Gen, Iran,) according to manufacturer's instruction. The quality and quantity of final extracted DNA were checked on $1 \%$ agarose gel electrophoresis stained with ethidium bromide and Nanodrop ND-1000 spectrophotometer (Nanodrop Technologies, Wilmington, DE, USA) at a wavelength of 230, 260 and $280 \mathrm{~nm}(36)$.

Gene amplification. In Escherichia coli the ompF gene encodes a major outer membrane porin protein that is differentially regulated by the OmpR protein. OmpR acts as a positive as well as a negative regulator of ompF expression by binding to DNA sequences in the $o m p F$ promoter region. Set of primers used for PCR reaction of upstream and downstream regions ompF and PhyC genes of Bacillus subtilis are listed in Table 1. The amplification was done using Thermal Cycler (Mastercycler Gradient, Eppendorf, Germany), in the final reaction volume of $25 \mu \mathrm{l}$. The PCR mixture consisted of $1 \mu \mathrm{g}$ of DNA samples, $1 \mu \mathrm{M}$ of each primer, $200 \mu \mathrm{M}$ dNTPs, $200 \mu \mathrm{M} \mathrm{MgCl}, 1 \mathrm{U}$ of Smart Taq DNA polymerase (Fermentas, Germany) and $2.5 \mu \mathrm{l}$ of $10 \times$ PCR buffer (37). Amplification was performed in a thermal cycler and initiated with a pri- 
MAHDIYAR IRAVANI SAADI ET AL.

Table 1. Specific oligonucleotide primers and annealing temperature

\begin{tabular}{llc}
\hline Primer name & Sequence* & TM $\left({ }^{\circ} \mathbf{C}\right)$ \\
\hline ompF-up & F: 5'-ATGTCTAGAAGAAGATTTTGTGCCAGG -3' & $61^{\circ} \mathrm{C}$ \\
& R: 5'-CGTGGTACCTATTTATTACCCTCATGG -3' & \\
PhyC & F: 5'- TTAGGTACCATGAATCATTCAAAAACAC -3' & $61^{\circ} \mathrm{C}$ \\
& R: 5'- ATTGAGCTCTTATTTTCCGCTTCTGTCAGTC -3' & \\
ompF-down & F: 5'- GTAGAGCTCGCTTTGGTATCGTTGGTG -3' & $61^{\circ} \mathrm{C}$ \\
& R: 5'- GTGCTCGAGTTTTGTTGAAGTAGTAGG -3' & \\
\hline
\end{tabular}

*The underlined sequence are Restriction enzyme sites

mary denaturation step at $95^{\circ} \mathrm{C}$ for $5 \mathrm{~min}$, followed by 32 cycles of $94^{\circ} \mathrm{C}$ for $1 \mathrm{~min}, 61^{\circ} \mathrm{C}$ for $1 \mathrm{~min}$ and $72^{\circ} \mathrm{C}$ for $1 \mathrm{~min}$. The program was followed by a final extension at $72^{\circ} \mathrm{C}$ for $5 \mathrm{~min}$.

Evaluation of PCR products. The PCR products were run on $1 \%$ agarose gel and visualized by ethidium bromide staining. Electrophoresis buffer was TBE [Tris-base $10.8 \mathrm{~g}, 89 \mathrm{~mm}$, Boric acid 5.5 $\mathrm{g}, 2 \mathrm{~mm}$ and EDTA $4 \mathrm{ml}$ of $0.5 \mathrm{M}$ EDTA (pH 8.0)]. The Constant voltage of $85 \mathrm{~V}$ for $30 \mathrm{~min}$ was used for product separation. After electrophoresis, images were obtained in UVI doc gel documentation systems (UK). The amplified fragments were purified with gel extraction kit (Bineer Co., Korea), according to the manufacturer's protocol.

T/A cloning. The amplified products were cloned in pGEM-T easy vector (Promega Co.) and the resulting recombinant plasmids were used to transform into competent E. coli strain Top10F' (Escherichia coli TOP10F competent cells (Stratagene) was employed as the host for gene cloning and transformed cells were grown in LB medium with $100 \mu \mathrm{g} / \mathrm{mL}$ ampicillin) in Luria Bertani (LB) Medium (Merck KGaA, Germany). E. coli colonies carrying the recombinant vector were selected on LB medium with ampicillin (100 mg/ml). The presence of amplified $P h y C$ and upstream and downstream regions of $O m p F$ was confirmed by restriction enzyme analysis. Digestion and transformation procedures were performed according to the manufacturer's instructions.

Subcloning of the $P h y C$, downstream and upstream ompF and construction of expression vector pET32. The $384 \mathrm{bp}$ fragment of the upstream $O m p F$ gene from the recombinant plasmid (pGEM$O m p F$-up) ompF gene from the recombinant plas- mid (pGEM- OmpF -up) expression vector was also confirmed by digestion with XbaI and KpnI enzymes. Also, cloning vector ( $\mathrm{pET} 32$ ) were digested with XbaI and $K p n I$ and then ligated to generate the recombinant plasmid (pET32- OmpF -up). After preparation, the plasmid was transformed under heat shock $\left(42^{\circ} \mathrm{C}\right)$ and calcium chloride $\left(\mathrm{CaCl}_{2}\right)$ for the 90 seconds into E. coli strain TOP10F'. Extraction and purification of subcloned plasmids were done using $1.5 \%$ agarose gel electrophoresis using purification kit (Bioneer, South Korea) according to the manufacturer's instructions. All steps were performed for the $385 \mathrm{bp}$ fragment of downstream ompF and a 1171 bp fragment of PhyC genes, that were digested with SacI/XhoI and KpnI/ SacI, respectively. cloning vector (pET32) was introduced with T4 ligase to construct the recombinant plasmid (pET32- ompF -up) using a T/A cloning kit (DNA ligation kit mighty mix, TaKaRa). Escherichia coli TOP10F competent cells (Stratagene) was employed as the host for gene cloning and transformed cells were grown in LB medium with $100 \mu \mathrm{g} / \mathrm{mL}$ ampicillin. The detail protocol of cloning and transformation was followed as described previously $(36,37)$.

\section{RESULTS}

Gene amplification. Results of PCR-amplified products for $P h y C$ and the andupstream and downstream regions of ompF are shown in Fig. 1. The results showed that the B. subtilis and E. coli contained PhyC and upstream and downstream regions of $o m p F$, respectively.

T/A cloning. The recombinant plasmid was transformed into competent cells in LB medium containing ampicillin, then cloned contained $o m p F$-up and ompF-down regions and $P h y C$ gene was digested 
with XbaI/KpnI, SacI/XhoI and KpnI/SacI, respectively (Fig. 2).

Subcloning of the $\boldsymbol{P h y} \boldsymbol{C}$ gene. $O m p F$ gene regions and $P h y C$ gene, which has the restriction points of Xbal/ KpnI, SacI/XhoI and KpnI/SacI were inserted in the polyclonal site (PCS) in the pET32 plasmid. TOP10F' competent cells were used for transformation and culturing in LB medium containing ampicillin. The results of the pET32 vector contained

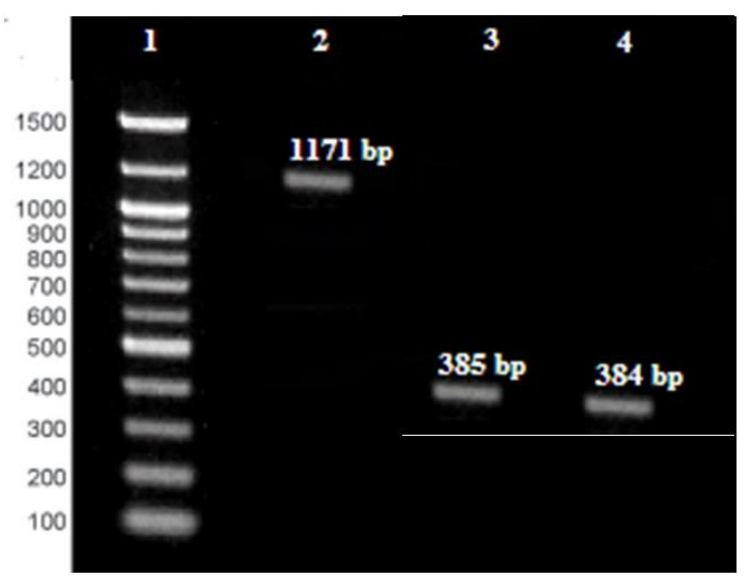

Fig. 1. Analysis of PCR amplified $P h y C$ and $O m p F$ gene products by agarose gel electrophoresis. Lane 1: $100 \mathrm{bps}$ DNA marker (Fermentas, Germany), lanes 2: 1171 bp PhyC gene fragment, lane 3: 385 bp ompF-down and lane 4: 384 bp omp $F$-up fragments.

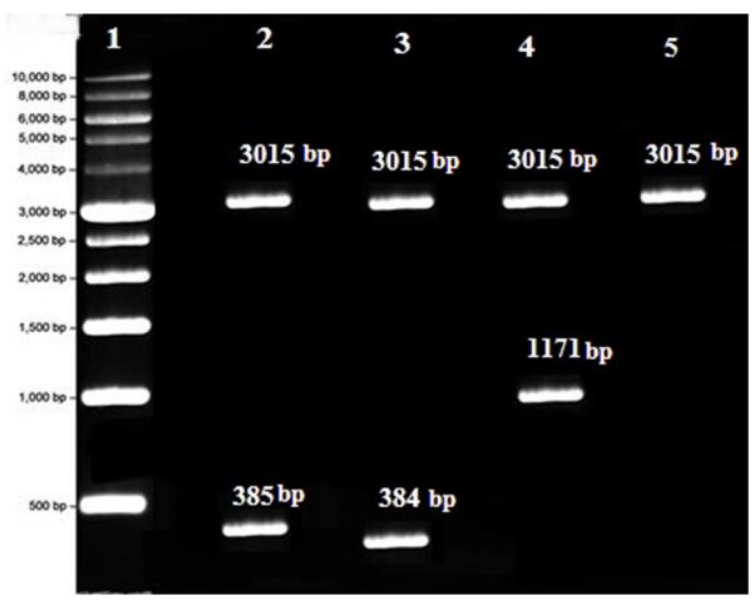

Fig. 2. Analysis of digested pGEM-PhyC plasmid by restriction enzymes. Lane 1: 1Kb DNA marker (Fermentas, Germany), lanes 2-4: pGEM- ompF- down, pGEM- ompFup and pGEM-PhyC were digested with SacI/XhoI, Xbal/ KpnI and KpnI/SacI respectively. Lane 5: 3015 bp pGEM-T easy vector. $o m p F$-up, $P h y C$ and $o m p F$-down genes were digested with XbaI/KpnI, KpnI/SacI and SacI/XhoI, respectively (Fig. 3A). The gene constructs $o m p F$-upPhyC-ompF-down digested with XbaI/XhoI restriction enzyme, to finally confirm subcloning (Fig. 3B).

\section{DISCUSSION}

Public knowledge of the environmental impact of organic agriculture has led to legislation that extends the measure of phosphate in the animal excretory product in certain parts of the world, and will likely be increased in other parts of the world in the near future. Under these circumstances, phytase will be extensively used in animal diets to improve phytate-P bioavailability and decrease $\mathrm{P}$ expulsion. The global market of phytase as an animal nourish additive is predictable to be 500 million dollars. The important movement has been made in the phytase investigation during the past 20 years. Transgenic mice expressing microbial phytase have been newly developed as a testable sample to work the usefulness of exogenous phytase expression (38).

Our systematic awareness of phytase has yet to profit a solution to meet its vast nourishing and environmental request. More investigation is needed into discovering novel phytases (39), although phytate as a single source of $\mathrm{P}$ has induced this generation. This finding proposes that this generation is induced only when inorganic phosphate is a limiting factor (40). Engineering improved phytases based on three-dimensional structure, and developing more cost-effective expression systems should be continued.

The PCR amplified 1171 base pair DNA fragment corresponding to the $P h y C$ gene from $B$. subtilis was cloned using T/A cloning vector. Successful cloning was achieved in transforming $E$. coli host selected on ampicillin-containing medium. The clones were confirmed using colony PCR and restriction digestion of positive clones with $\mathrm{XbaI} / \mathrm{Xhol}$ restriction enzyme, to final confirmed subcloning.

Considering catalytic properties, it is extremely desirable to have an operating system for the production of E. coli phytase for some reasons. First, the $\mathrm{pH}$ optimum is set more in the acid range than that of the frequently used B. subtillis phytases. Thus, the high activity of $E$. coli phytase can be used more excellently in the acidic environments of the digestive of simple-stomached animals (38). Another reason, 

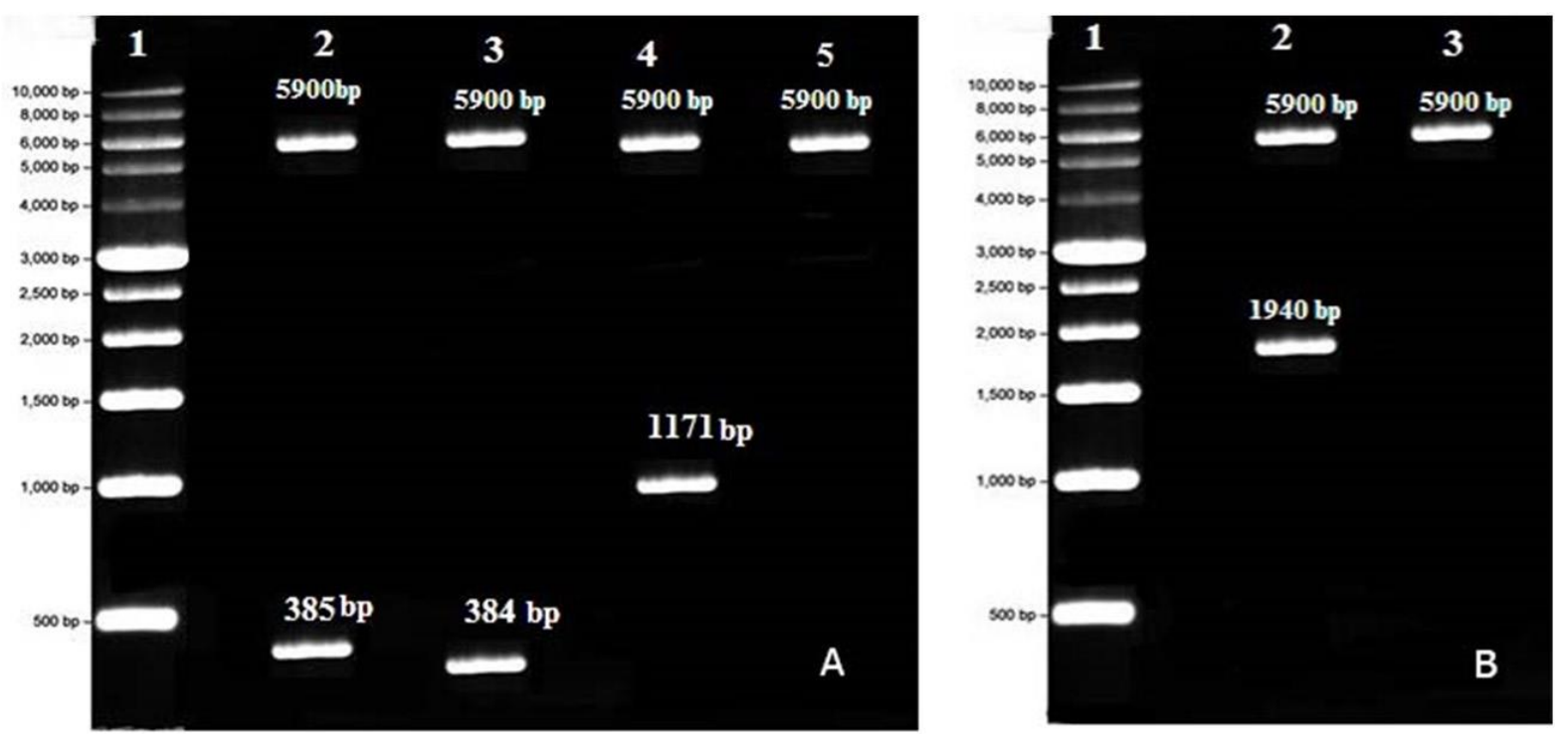

Fig. 3. Analysis of digested pET32-PhyC plasmid of restriction enzymes. Lane 1: 1Kb DNA marker (Fermentas, Germany), lanes 2-4: pET32- ompF- down, pET32- ompF- up and pET32-PhyC were digested with SacI/XhoI, Xbal/KpnI and KpnI/SacI respectively. Lane 5: 5900 bp pET32 vector. B. Final confirmed gene construct. Lane 1: $1 \mathrm{~Kb}$ DNA marker (Fermentas, Germany), lane 2: gene constructs digested, that 1940 bp belong to ompF- up -PhyC-ompF- down construct and 5900 bp pET32 vector, lane 3: pET32 supercoil vector.

E. coli phytase has the maximum specific activity of all phytases tested so far. Third, the E. coli phytase in contrast to B. subtillis phytase, is resistant to protolithic degradation in the intestines. This article focused on numerous phytases that had been from multiple sources rather than the searches of the basic factors affecting variability in phytase reaction. An essential material in respect of phytate and phytase is lacking in many parts, which needs to be combined and produced for a more complete conception of this topic. The original phytase feed enzymes were produced generally from fungi. But recent expansions in the production of enzymes in other forms of microorganisms, such as yeast and bacteria, have led to new exogenous phytases (41).

In the current study, the results are in agreement with the results of earlier studies in different nations. In 2008, Rao et al. isolated and cloned a novel PhyC from Bacillus subtilis in E. coli; to recover the active enzyme from inclusion bodies, and to describe the recombinant $P h y C$ (1). However, the kind of $P h y C$ was produced at slower rate levels (42). In 2009 Ozusaglam and Ozcan reported the phytase from B. subtilis VTT E-68013 was not expressed in $B$. coagulans. Though, this was the first report to our knowledge that $P h y C$ was searched to clone in $B$. coagulans (43). Tran et al. (2009) reported the cloning of thermostable alkaline PhyC from a newly isolated Bacillus subtilis MD2 in E. coli (35).

Guerrero-Olazarán et al. in 2010 investigated cloning and expression of a Bacillus Phytase C Gene in Pichia pastoris and reported were cloned and inserted. Also, they showed that both recombinant and native phytases were calcium concentration and $\mathrm{pH}$-dependent (42).

pMK3P isolated from E. coli was used to introduce into B. coagulans DSM1 by Electro transformation (44). And Ozusagla et al. have cloned this gene from B. subtilis VTT E-68013 in L. plantarum strain 755 (43). In 2007 the cloning phytase was used in animal feeding. Moreover, they demonstrated that reduced phosphorus pollution of animal waste and improved phosphorus nutrition (39). In another study, the PhyC gene of $P$. syringae MOK1 cloned and sequenced, and recombinant expressed the Phytase in E. coli (16). The E. coli pET expression system was able to express Phytases of E. coli and Bacillus subtilis origins (38). The expressed Bacillus subtilis Phytase accounted for $20 \%$ of the total soluble proteins in $E$. coli (24).

The purpose of the present study was to isolate the phyC gene. B. subtilis was selected that produces phytase. The defined aims of the study were isolated via a Phytase-producing Bacillus strain, the 
corresponding gene was cloned and developed an efficient and biologically safe production system for the enzyme in the later step. As no single phytase or expression system is likely to be able to meet the various needs for this enzyme, several methods, such as using along with microbial, plant phytase reproduction or low-phytic acid corn, may be the right direction to pursue.

\section{ACKNOWLEDGEMENTS}

The authors would like to express their deep sense of gratitude and sincere thanks to the staff of the Biotechnology Research Center of the Islamic Azad University of Shahrekord Branch in Iran.

\section{REFERENCES}

1. Rao DE, Rao KV, Reddy VD. Cloning and expression of Bacillus phytase gene (phy) in Escherichia coli and recovery of active enzyme from the inclusion bodies. $J$ Appl Microbiol 2008;105:1128-1137.

2. Singh N, Kuhar S, Priya K, Jaryal R, Yadav R (2018). Phytase: The feed enzyme, an overview. Advances in Animal Biotechnology and Its Applications. pp: 269327.

3. Farhat-Khemakhem A, Farhat MB, Boukhris I, Bejar W, Bouchaala K, Kammoun R, et al. Heterologous expression and optimization using experimental designs allowed highly efficient production of the PHY US417 phytase in Bacillus subtilis 168. AMB Express 2012;2:10.

4. Bhavsar K, Gujar P, Shah P, Kumar VR, Khire JM. Combinatorial approach of statistical optimization and mutagenesis for improved production of acidic phytase by Aspergillus niger NCIM 563 under submerged fermentation condition. Appl Microbiol Biotechnol 2013;97:673-679.

5. Nielsen AV, Tetens I, Meyer AS. Potential of phytase-mediated iron release from cereal-based foods: a quantitative view. Nutrients 2013;5:3074-3098.

6. Dersjant-Li Y, Awati A, Schulze H, Partridge G. Phytase in non-ruminant animal nutrition: a critical review on phytase activities in the gastrointestinal tract and influencing factors. J Sci Food Agric 2015;95:878-896.

7. Morgan NK, Walk CL, Bedford MR, Scholey DV, Burton EJ. Effect of feeding broilers diets differing in susceptible phytate content. Anim Nutr 2016;2:33-39.

8. Boehm Jr JD, Walker FR, Bhandari HS, Kopsell D,
Pantalone VR. Seed inorganic phosphorus stability and agronomic performance of two low-phytate soybean lines evaluated across six southeastern US environments. Crop Sci 2017;57:2555-2563.

9. Haros M, Bielecka M, Honke J, Sanz Y. Myo-inositol hexakisphosphate degradation by Bifidobacterium infantis ATCC 15697. Int J Food Microbiol 2007;117:7684.

10. Lan GQ, Abdullah N, Jalaludin S, Ho YW. Culture conditions influencing phytase production of Mitsuokella jalaludinii, a new bacterial species from the rumen of cattle. J Appl Microbiol 2002;93:668-674.

11. Haefner S, Knietsch A, Scholten E, Braun J, Lohscheidt $\mathrm{M}$, Zelder O. Biotechnological production and applications of phytases. Appl Microbiol Biotechnol 2005;68:588-597.

12. Wang Q, Fu SJ, Sun JY, Weng XY. Characterization of a thermostable alkaline phytase from Bacillus licheniformis ZJ-6 in Pichia pastoris. World J Microbiol Biotechnol 2011;27:1247-1253.

13. Ries EF, Alves Macedo G. Improvement of phytase activity by a new Saccharomyces cerevisiae strain using statistical optimization. Enzyme Res 2011;2011: 796394.

14. Vohra A, Satyanarayana T. Phytase production by the yeast, Pichia anomala. Biotechnol Lett 2001;23:551554.

15. Azeem M, Riaz A, Chaudhary AN, Hayat R, Hussain Q, Tahir MI, et al. Microbial phytase activity and their role in organic P mineralization. Arch Agron Soil Sci 2015;61:751-766.

16. Nakamura Y, Fukuhara H, Sano K. Secreted phytase activities of yeasts. Biosci Biotechnol Biochem 2000;64:841-844.

17. Huang H, Luo H, Yang P, Meng K, Wang Y, Yuan T, et al. A novel phytase with preferable characteristics from Yersinia intermedia. Biochem Biophys Res Commun 2006;350:884-889.

18. Bekalu ZE, Madsen CK, Dionisio G, Brinch-Pedersen $\mathrm{H}$. Aspergillus ficuum phytase activity is inhibited by cereal grain components. PLoS One 2017;12(5):e0176838.

19. Han N, Miao H, Yu T, Xu B, Yang Y, Wu Q, et al. Enhancing thermal tolerance of Aspergillus niger PhyA phytase directed by structural comparison and computational simulation. BMC Biotechnol 2018;18:36.

20. Quan CS, Tian WJ, Fan SD, Kikuchi J. Purification and properties of a low-molecular-weight phytase from Cladosporium sp. FP-1. J Biosci Bioeng 2004;97:260266.

21. Hamada A, Yamaguchi K, Ohnishi N, Harada M, Nikumaru S, Honda H. High-level production of yeast (Schwanniomyces occidentalis) phytase in transgenic rice plants by a combination of signal sequence and co- 
don modification of the phytase gene. Plant Biotechnol J 2005;3:43-55.

22. Tye AJ, Siu FK, Leung T, Lim B. Molecular cloning and the biochemical characterization of two novel phytases from B. subtilis 168 and B. licheniformis. Appl Microbiol Biotechnol 2002;59:190-197.

23. Priyodip P, Prakash PY, Balaji S. Phytases of probiotic bacteria: characteristics and beneficial aspects. Indian J Microbiol 2017;57:148-154.

24. Singh S, Singh S, Sharma PK, Sharma D. Isolation, identification and molecular characterization of phytase producing bacteria, Pseudomonas sp. aazad. $J$ Pure Appl Microbiol 2017;11:1845-1850.

25. Roy MP, Mazumdar D, Dutta S, Saha SP, Ghosh S. Cloning and expression of phytase appA gene from Shigella sp. CD2 in Pichia pastoris and comparison of properties with recombinant enzyme expressed in $E$. coli. PLoS One 2016;11(1):e0145745.

26. Hong CY, Cheng KJ, Tseng TH, Wang CS, Liu LF, Yu SM. Production of two highly active bacterial phytases with broad $\mathrm{pH}$ optima in germinated transgenic rice seeds. Transgenic Res 2004;13:29-39.

27. Shamna KS, Rajamanikandan KCP, Mukesh Kumar DJ, Balakumaran MD, Kalaichelvan PT. Extracellular production of phytases by a native Bacillus subtilis strain. Ann Biol Res 2012;3:979-987.

28. Gulati HK, Chadha BS, Saini HS. Production and characterization of thermostable alkaline phytase from Bacillus laevolacticus isolated from rhizosphere soil. $J$ Ind Microbiol Biotechnol 2007;34:91-98.

29. Barbe V, Cruveiller S, Kunst F, Lenoble P, Meurice G, Sekowska A, et al. From a consortium sequence to a unified sequence: the Bacillus subtilis 168 reference genome a decade later. Microbiology (Reading) 2009;155:1758-1775.

30. Liu J, Fang C, Jiang Y, Yan R. Characterization of a hemolysin gene ytjA from Bacillus subtilis. Curr Microbiol 2009;58:642-647.

31. Heinzmann S, Entian KD, Stein T. Engineering $B a$ cillus subtilis ATCC 6633 for improved production of the lantibiotic subtilin. Appl Microbiol Biotechnol 2006;69:532-536.

32. Swain M, Ray R. Alpha-amylase production by Bacillus subtilis CM3 in solid state fermentation using cassava fibrous residue. J Basic Microbiol 2007;47:417425.

33. Chang CT, Fan MH, Kuo FC, Sung HY. Potent Fibrinolytic Enzyme from a Mutant of Bacillus s ubtilis IMRNK1. J Agric Food Chem 2000;48:3210-3216.

34. Earl AM, Losick R, Kolter R. Ecology and genomics of Bacillus subtilis. Trends Microbiol 2008;16:269-275.

35. Tran TT, Mamo G, Mattiasson B, Hatti-Kaul R. A thermostable phytase from Bacillus sp. MD2: cloning, expression and high-level production in Escherichia coli. J Ind Microbiol Biotechnol 2010;37:279-287.

36. Sambrook J, Fritsch EF, Maniatis T (1989). Molecular cloning: a laboratory manual 2nd ed. Cold spring harbor laboratory press.

37. Zimmerman SA, Tomb JF, Ferry JG. Characterization of CamH from Methanosarcina thermophila, founding member of a subclass of the \{gamma\} class of carbonic anhydrases. J Bacteriol 2010;192:1353-1360.

38. Golovan S, Wang G, Zhang J, Forsberg CW. Characterization and overproduction of the Escherichia coli appA encoded bifunctional enzyme that exhibits both phytase and acid phosphatase activities. Can J Microbiol 2000;46:59-71.

39. Lei XG, Porres JM. Phytase enzymology, applications, and biotechnology. Biotechnol Lett 2003;25:1787-1794.

40. Bikker P, Spek JW, Van Emous RA, Van Krimpen MM. Precaecal phosphorus digestibility of inorganic phosphate sources in male broilers. Br Poult Sci 2016;57:810-817.

41. Selle PH, Ravindran V. Microbial phytase in poultry nutrition. Anim Feed Sci Technol 2007;135:1-41.

42. Kumar V, Yadav AN, Verma P, Sangwan P, Saxena A, Kumar K, et al. $\beta$-Propeller phytases: diversity, catalytic attributes, current developments and potential biotechnological applications. Int J Biol Macromol 2017;98:595-609.

43. Ozusaglam MA, Ozcan N. Cloning of phytase gene in probiotic bacterium Bacillus coagulans. Adv Studies Biol 2009;1:15-24.

44. Bawane R, Tantwai K, Rajput LPS, Kadam-Bedekar M, Kumar S, Gontia I, et al. Molecular analysis of phytase gene cloned from Bacillus subtilis. Adv Stud Biol 2011;3:103-110. 